\title{
Feeding study for the mycotoxin zearalenone in yellow mealworm (Tenebrio molitor) larvae-investigation of biological impact and metabolic conversion
}

\author{
Kelly Niermans ${ }^{1} \cdot$ Jan Woyzichovski ${ }^{2} \cdot$ Nina Kröncke $^{2} \cdot$ Rainer Benning $^{2} \cdot$ Ronald Maul $^{1,2}$
}

Received: 24 October 2018 / Revised: 18 February 2019 / Accepted: 25 February 2019 / Published online: 13 March 2019

(C) The Author(s) 2019

\begin{abstract}
Edible insects as additional food and/or feed source may represent one important component to solve the problem of food security for a growing human population. Especially for covering the rising demand for protein of animal origin, seven insect species currently allowed as feed constituents in the European Union are gaining more interest. However, before considering insects such as yellow mealworm larvae (Tenebrio molitor) as suitable for, e.g. human consumption, the possible presence and accumulation of contaminants must be elucidated. The present work investigates the effects of the mycotoxin zearalenone (ZEN) and its metabolites on insect larvae. Seven different diets were prepared: toxin-free control, spiked and artificially contaminated (both containing approx.500 $\mu \mathrm{g} / \mathrm{kg}$ and approx. $2000 \mu \mathrm{g} / \mathrm{kg}$ of ZEN) as well as two naturally contaminated diets $(600 \mu \mathrm{g} / \mathrm{kg}$ and $900 \mu \mathrm{g} / \mathrm{kg}$ ZEN). The diets were used in a multiple-week feeding trial using T. molitor larvae as model insects. The amount of ZEN and its metabolites in the feed, larvae and the residue were measured by HPLC-MS/MS. A significantly enhanced individual larval weight was found for the insects fed on the naturally contaminated diets compared to the other feeding groups after 8 weeks of exposure. No ZEN or ZEN metabolites were detected in the T. molitor larvae after harvest. However, ZEN, $\alpha$ and $\beta$-stereoisomers of zearalenol were found in the residue samples indicating an intense metabolism of ZEN in the larvae. No further ZEN metabolites could be detected in any sample. Thus, ZEN is not retained to any significant amount in T. molitor larvae.
\end{abstract}

Keywords Tenebrio molitor $\cdot$ Yellow mealworm $\cdot$ Zearalenone $\cdot \alpha$-ZEL $\cdot \beta$-ZEL $\cdot$ Phase II metabolites

\section{Introduction}

The continuous growth of the world population increases the global demand for food, land, water and energy (Godfray et al. 2010). Consequently, van Huis et al. (2013) stated that the food production must grow, while at the same time, the environmental impact of both agriculture and livestock must decrease (Foley et al. 2011; van Huis et al. 2013). A change of diet was one of the solutions proposed (Godfray et al. 2010). Edible insects were suggested as an additional food source due to their favourable nutritional properties including high

Ronald Maul

Ronald.Maul@bfr.bund.de

1 BfR - German Federal Institute for Risk Assessment, Max-Dohrn-Str. 8-10, 10589 Berlin, Germany

2 University of Applied Sciences Bremerhaven, An der Karlstadt 8, 27568 Bremerhaven, Germany protein, fat and mineral contents (Rumpold and Schluter 2013; van Huis 2013; van Huis et al. 2013). Additionally, insects reproduce quickly; have high feed conversion efficiency, a low environmental footprint and low water consumption; and there is a possibility to rear them on waste substrates (Bovera et al. 2015; van Huis et al. 2013). Therefore, the use of certain insect species can provide in the increasing demand for animal-derived proteins. These insect-derived proteins can additionally be used in feed processing and completely or partly substitute fishmeal and soy due to their current high prices (Bovera et al. 2015). Furthermore, the availability of fishmeal and soy in the future will be limited; therefore, alternatives must be found (Makkar et al. 2014).

Insects belong to the group of phylum Arthropoda, consist of a wide variety of animals and serve in different stages of the feed and food production chain. This diversity consequently displays the complexity and main challenge of implementing insects in the food and feed production chain (Van der FelsKlerx et al. 2016; van Raamsdonk et al. 2017). Within the EU, 
insects supposed to be used as food are mostly under the Novel Food Regulation and therefore need authorization before allowance on the European market (European Parliament and the Council of the European Union 2015). Additionally for feed, the processed animal proteins of only seven farmed insect species may be used (European Commission 2017). The yellow mealworm (Tenebrio molitor), which is the larval stage of Darkling beetles, is one of the allowed species (European Commission 2017). Additionally, the European law lays down rules on the use of substrates, stating that substrates for feeding insects may only contain products of nonanimal material or category 3 animal origin material (European Commission 2017; European Parliament and the Council of the European Union 2009a, b). In practice, insects are often nourished on cereal side products, which might contain high amounts of mycotoxins.

In this study, the focus is placed on zearalenone (ZEN) and its metabolites. ZEN is a macrocyclic $\beta$-resorcyclic acid lactone and is produced as a secondary metabolite by many Fusarium species (Hueza et al. 2014). A lot is already known on the effect and metabolism of ZEN in vertebrates. After ingestion, ZEN is metabolised by the intestinal tissue and hepatocytes. In the intestinal cells, the keto group on C-8 is reduced to $\alpha-, \beta$ zearalenol (ZEL) and biotransformation into the metabolites $\alpha$-, $\beta$-zearalanol (ZAL) and zearalanone (ZAN) is initiated (Fig. 1) (Hagler et al. 1979; Kinani et al. 2008; Metzler et al. 2010). ZEN and its metabolites are considered as endocrine disruptors due to their chemical structure which resembles the female hormone $17 \beta$-estradiol and makes oestrogen receptor binding possible (Kinani et al. 2008).
Additionally, ZEN and its metabolites may also be present in conjugated, e.g. sulfated form, either, insoluble and attached to macromolecules or as soluble conjugates (modified mycotoxins) (Berthiller et al. 2009; Binder et al. 2017; Keller et al. 2018; Rychlik et al. 2014; Warth et al. 2015). These modified forms can be obtained after metabolism or by transformation caused by chemical detoxification processes (Berthiller et al. 2013; Hussein and Brasel 2001; Warth et al. 2015). Excretion profiles obtained from previously conducted studies show that there is a significant difference in urinary excretion, glucuronidation or conjugation with sulfate of respectively deoxynivalenol (DON) and ZEN between animal species (EFSA 2017; Guerre 2015; Keller et al. 2018; Maul et al. 2012; Prelusky et al. 1986). Additionally, the metabolism of insects is known to be only distantly related to metabolic processes known from mammals or microorganisms (Binder et al. 2017; Ji et al. 2016; Keller et al. 2018; Malekinejad et al. 2006; Pfeiffer et al. 2007). Nevertheless, the presence of enzymes for phase I metabolism, e.g. cytochrome P450 monooxygenases or dehydrogenases as well as certain phase II enzymes such as sulfotransferases or glycosyltransferases, is described for insects as well (Ahn et al. 2012; Swevers et al. 1990; Vakiani et al. 1998). Furthermore, it is described that ZEN does not appear to have an obvious oestrogen-related target site in insects (Bhatnagar et al. 1991). However, high concentrations of ZEN have shown to contain weak antagonist properties towards ecdysone, a steroid hormone found in insects which regulates development and moulting (Dinan et al. 2001).

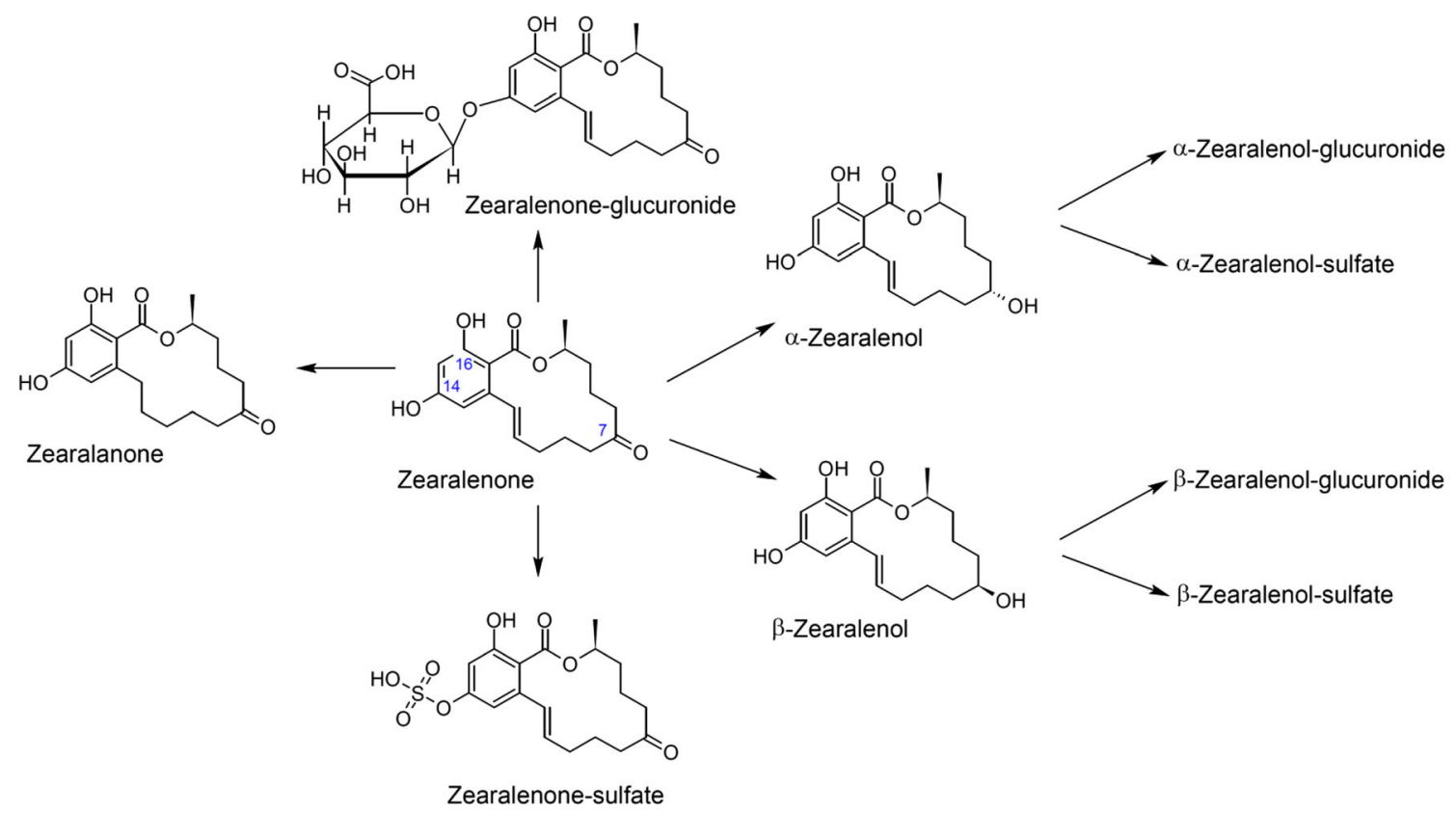

Fig. 1 Metabolic pathway of zearalenone. Shown are only the C-14-linked glucuronides and sulfates. C-16 conjugates may also be formed and are known from in vitro studies (Metzler et al. 2010) 
The oestrogenic activity of ZEN and its modified forms differ remarkably. Therefore, the European Food Safety Authority determined relative potency factors for ZEN and its modified forms. Compared to ZEN (set at 1.0), the relative potency factors of its metabolites are respectively 60 for $\alpha$ ZEL, 4.0 for $\alpha$-ZAL, 2.0 for $\beta$-ZAL, 1.5 for ZAN, 0.2 for $\beta$ ZEL. Additionally, the relative potency factors for glucuronides and sulfates are corresponding to their parent compound (EFSA 2016, 2017; Hagler et al. 1979; Metzler et al. 2010; Shier et al. 2001).

Contamination usually occurs in the field but can also occur during poor storage conditions of cereal-derived products. Maximum allowed levels for ZEN range from $50 \mu \mathrm{g} / \mathrm{kg}$ in processed grain products for human consumption to $350 \mu \mathrm{g} / \mathrm{kg}$ for unprocessed maize (EFSA 2011). ZEN was found in wheat and maize samples throughout Europe, in concentrations ranging from $15 \mu \mathrm{g} / \mathrm{kg}$ to as high as $5700 \mu \mathrm{g} / \mathrm{kg}$ after a year with a particularly wet summer (Hoogenboom et al. 2008; Schollenberger et al. 2006; Scudamore and Patel 2000). The maximum tolerable daily intake (TDI) of ZEN was previously established on $0.5 \mu \mathrm{g} / \mathrm{kg}$ body weight by the Joint FAO/ WHO Expert Committee on Food Additives in 2000, and on $0.2 \mu \mathrm{g} / \mathrm{kg}$ body weight by the Scientific Committee on Food. More recently, the Panel on Contaminants in the Food Chain derived a TDI of $0.25 \mu \mathrm{g} / \mathrm{kg}$ body weight (EFSA 2011). Since 2016, the modified forms of ZEN were included in a group-TDI of $0.25 \mu \mathrm{g} / \mathrm{kg}$ body weight (EFSA 2016).

Previously performed studies showed that ZEN does not accumulate in the larval body of the lesser mealworm (Alphitobius diaperinus), which seems to be able to metabolise ZEN and excrete the mycotoxins (Camenzuli et al. 2018). Additionally, the nematode Caenorhabditis elegans appears to be able to metabolise zearalenone-14sulfate (ZEN14Sulf) in $\alpha$ - and/or $\beta$-zearalenol-sulfate (ZELSulf) (Keller et al. 2018). However, comprehensive investigation on ZEL metabolism in T. molitor is lacking. Other studies addressing the effect of mycotoxins on insects include DON, aflatoxins and ochratoxin A (Bosch et al. 2017; Camenzuli et al. 2018; Van Broekhoven et al. 2017). Therefore, this study focusses on the impact of ZEN and some possible metabolites on T. molitor. Aims of the presented work were (i) to evaluate the overall recovery of ZEN as a further important Fusarium mycotoxin fed to T. molitor larvae in different diets, (ii) the evaluation of the effects on the larvae and (iii) the screening for potential metabolites.

\section{Materials and methods}

\section{Materials and chemicals}

Analytical standards were purchased from Romer Labs (Getzersdorf, Austria): ZEN and from Merck (Darmstadt,
Germany): $\alpha$-ZEL, $\beta$-ZEL, ZAN, $\beta$-ZAL, DON. ${ }^{13} \mathrm{C}$-labelled standards were purchased from Biozol (Eching, Germany): ZEN (certified purity 99.5\%), DON (certified purity 99.5\%), $\beta$-ZEL (certified purity $96 \%$ ) and $\alpha$-ZEL (certified purity $96 \%$ ).

Methanol, acetonitrile $(\mathrm{ACN})$, acetic acid ( $\mathrm{HAc})$, formic acid (FA), ammonium formate $\left(\mathrm{NH}_{4} \mathrm{COOH}\right)$ and magnesium sulfate $\left(\mathrm{MgSO}_{4}\right)$ were purchased from Merck (Darmstadt, Germany). Double-deionised water was obtained through the use of a water-filtering machine (Milli-Pore, Merck).

\section{Samples}

Mycotoxin-free whole-wheat grains were bought at a local supermarket (BIO Weizen) and milled to grain flour (ring sieve pore size: $0.5 \mathrm{~mm}$ ) using an Ultra-Centrifugal mill ZM200 (Retsch, Haan, Germany). Artificially contaminated wheat flour was obtained as previously described by Borzekowski et al. (2018) for the inoculation of rice. In brief, moistened wheat grain flour was autoclaved and inoculated with Fusarium graminearum (strain F1 as described by Dubos et al. 2011) and incubated for 21 days. Subsequently, the flour was autoclaved to terminate the incubation, freeze dried and milled again for homogenisation. The resulting toxin-rich flour contained $541.4 \mathrm{mg} / \mathrm{kg}$ ZEN, $3.0 \mathrm{mg} / \mathrm{kg} \alpha$-ZEL, $11.4 \mathrm{mg} / \mathrm{kg} \beta$-ZEL, $6.4 \mathrm{mg} / \mathrm{kg}$ ZAN and $3.4 \mathrm{mg} / \mathrm{kg} \beta-Z A L$ respectively (Borzekowski et al. 2018). Additionally, a wheat lot naturally contaminated with ZEN was provided by the European Reference Laboratory for mycotoxins (Geel, Belgium). The wheat was milled as described above and contained $0.84 \mathrm{mg} / \mathrm{kg}$ ZEN.

\section{Diet preparation}

The control, artificially and naturally contaminated wheat flour samples used for the insect feeding were either spiked or mixed in different ratios to obtain seven diets and contained different amounts of ZEN as is shown in Table 1. Spiked feed S1 and S2 was obtained by spiking blank wheat flour with toxin solution at two different concentration levels. A1 and A2 were obtained from blending blank wheat flour with two different amounts of the high concentrated artificially contaminated wheat flour, and N1 was obtained from blending the naturally contaminated wheat flour with the blank wheat flour. The samples were homogenised in by shaking overnight in a turbula mixer (WAB GmbH, Nidderau-Heldenbergen, Germany) and considered homogenous as two random samples showed less than $20 \%$ deviation for the content. Additionally, the amount of starch present in the wheat samples was measured with the ENZYTEC ${ }^{\text {TM }}$ starch kit (E1268) obtained from R-Biopharm (Darmstadt, Germany). Protein content was determined by use of the Kjeldahl method. 
Table 1 Feed composition and amounts of deoxynivalenol (DON), zearalenone (ZEN), $\alpha$-zearalenol ( $\alpha$-ZEL) and $\beta$-zearalenol ( $\beta$-ZEL) present in the different feed types prepared

\begin{tabular}{lllllllll}
\hline Wheat composition & & Code & DON $(\mu \mathrm{g} / \mathrm{kg})$ & ZEN $(\mu \mathrm{g} / \mathrm{kg})$ & $\alpha-Z E L(\mu \mathrm{g} / \mathrm{kg})$ & $\beta-\mathrm{ZEL}(\mu \mathrm{g} / \mathrm{kg})$ & Protein $(\mathrm{g} / 100 \mathrm{~g})$ & $\mathrm{Starch}(\mathrm{g} / 100 \mathrm{~g})$ \\
\hline Blank control & & $\mathrm{C}$ & 572.0 & $<$ LOQ & nd & nd & 9.9 & 53.6 \\
Blank spiked & Low & S1 & 568.4 & 588.5 & nd & nd & $9.9 \mathrm{a}$ & $53.6^{\mathrm{a}}$ \\
Blank spiked & High & S2 & 576.5 & 2254 & nd & $<$ LOQ & $9.9^{\mathrm{a}}$ & $53.6^{\mathrm{a}}$ \\
Blank + artificially contaminated & Low & A1 & 939.0 & 427.0 & nd & 11.3 & $9.9^{\mathrm{b}}$ & $50.7^{\mathrm{b}}$ \\
Blank + artificially contaminated & High & A2 & 2101 & 2283 & nd & 76.2 & 9.9 & 50.7 \\
Blank + naturally contaminated & Low & N1 & 2854 & 602.3 & nd & $<$ LOQ & $11.5^{\mathrm{b}}$ & $47.0^{\mathrm{b}}$ \\
Naturally contaminated & High & N2 & 4588 & 919.3 & nd & $<$ LOQ & 12.3 & 44.5 \\
\hline
\end{tabular}

$n d$ not detected, therefore either not present or not present in detectable levels (LOQs are ZEN: $10.9 \mu \mathrm{g} / \mathrm{kg} ; \mathrm{DON}: 67.1 \mu \mathrm{g} / \mathrm{kg}, \alpha-\mathrm{ZEL}: 11.2 \mu \mathrm{g} / \mathrm{kg} ; \beta$ ZEL LOQ was comparable to $\alpha$-ZEL and not determined separately)

${ }^{a}$ Not measured, however composed of the blank material by spiking, therefore assumed to be the same

${ }^{\mathrm{b}}$ Not measured directly, however calculated according to the blending protocol of two samples with measured content

\section{Preparation stock and working solutions}

Both a standard mix (ZEN, $\alpha$-ZEL, $\beta$-ZEL, ZAN, $\beta$-ZAL, DON) and an isotopically labelled standard (IS) mix (ZEN, $\alpha$-ZEL, $\beta$-ZEL) were prepared in ACN $1 \%$ HAc. The standard mix diluted by ACN $1 \%$ HAc served as calibration mix as well as spiking solution for validation. Calibration solutions were prepared by adding $180 \mu \mathrm{L} \mathrm{H}_{2} \mathrm{O}, 160 \mu \mathrm{L}$ ACN $1 \% \mathrm{HAc}$, $20 \mu \mathrm{L}$ of one out of eight calibration stock solutions and $40 \mu \mathrm{L}$ of the IS solution.

\section{Larval selection, exposure and harvest}

T. molitor larvae (family of Tenebrionidae), of Hochschule Bremerhaven's own breeding, were initially kept on wheat bran as substrate and selected at an age of 42 days and on medium size (approx. $1 \mathrm{~cm}$ ). Feeding groups, each containing 100 individuals, with an average weight of $7.80 \pm 0.9 \mathrm{mg}$ per individual were assembled in clear $400 \mathrm{~mL}$ glass beakers and incubated at $25{ }^{\circ} \mathrm{C}$ with a humidity of $75 \%$ with no day/night rhythm for light, temperature and humidity.

Exposure time was either 4 weeks (short-term, 70 days old larvae) or 8 weeks (long-term, 98 days old larvae). Each feeding group was fed with portions of 5-6 $\mathrm{g}$ of feed as soon as the feed in the beaker had been consumed. The exact amount of feed was recorded separately for every insect group. Biological triplicates were obtained for the seven diets prepared. Biological triplicates of the short-term exposed samples consisted of 200 individuals in order to obtain sufficient sample amount for further mycotoxin analysis (i.e. three times two groups were pooled) whereas biological triplicates of the longterm exposure included 100 individuals. Thus, for short-term as well as for long-term exposure for each of the seven diets, three replicate larvae and residue samples were obtained for analysis. After harvest and fasting for $24 \mathrm{~h}$, the larvae were stored at $-18{ }^{\circ} \mathrm{C}$ before freeze drying in a Beta $1-8$ LDplus freeze dryer (CHRIST, Osterode am Harz, Germany). The residue (combination of faeces and residual feed present in the beakers after the experiments) was kept separately and analysed for its mycotoxin content.

\section{Sample extraction}

The extraction methods used are based on a pre-norm nonquantitative high-performance liquid chromatography (HPLC) tandem mass spectrometry (MS/MS) screening method developed by CEN/TC 275/WG5 in project number 05701704 .

\section{Wheat extraction}

The wheat was grinded in a Retsch Ultra-Centrifugal mill ZM200 (Haan, Germany) at a particle size of $0.5 \mathrm{~mm}$. Homogenised dry wheat meal (2.5 g) was weighed in duplicates into a 50-ml Falcon tube and extracted using $5 \mathrm{ml} \mathrm{H}_{2} \mathrm{O}$ and $5 \mathrm{ml} \mathrm{ACN} 0.1 \%$ FA. Following, the samples were shaken for $30 \mathrm{~min}$, centrifuged $\left(30 \mathrm{~min} ; 5833 \times \mathrm{g} ; 10^{\circ} \mathrm{C}\right)$ and $1 \mathrm{ml}$ of

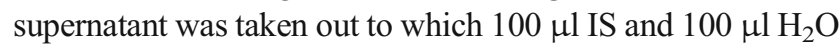
was added. Phase separation of organic and water phase was achieved by addition of $250 \mathrm{mg}$ anhydrous $\mathrm{MgSO}_{4}$, shaking for $30 \mathrm{~s}$ (VXR B, IKA) and centrifugation at $17,530 \times \mathrm{g}$ for $10 \mathrm{~min}$ at $10{ }^{\circ} \mathrm{C}$ (Microfuge R, Beckmann). Supernatant $(300 \mu \mathrm{l})$ was transferred into a HPLC crimp vial, mixed with $300 \mu \mathrm{H}_{2} \mathrm{O}$ and either directly measured or stored at $3{ }^{\circ} \mathrm{C}$ for up to 6 days.

\section{Larvae/residue sample extraction}

Larval samples were grinded in a Planetary Micro Mill, Pulverisette 7 premium line (FRITSCH GmbH, IdarOberstein, Germany). A variation on the method for multi mycotoxin extraction in wheat was used for larval and residue 
extractions. Two hundred milligrams of either grinded larvae or residue was weighed in duplicates into a 7-ml glass vial and extracted using $1.5 \mathrm{ml} \mathrm{H}_{2} \mathrm{O}$ and $1.5 \mathrm{ml} \mathrm{ACN} 0.1 \%$ FA. Following, the samples were mixed for $10 \mathrm{~min}$ in an ultrasonic bath, shaken for $30 \mathrm{~min}$, centrifuged $\left(30 \mathrm{~min} ; 5833 \times \mathrm{g} ; 10^{\circ} \mathrm{C}\right.$ ) and $1 \mathrm{ml}$ of supernatant was taken out to which $100 \mu \mathrm{l}$ IS and $100 \mu \mathrm{H}_{2} \mathrm{O}$ was added. Phase separation of organic and water phase was achieved by addition of $250 \mathrm{mg}$ anhydrous $\mathrm{MgSO}_{4}$, shaking for $30 \mathrm{~s}$ (VXR B, IKA) and centrifugation at $17,530 \times \mathrm{g}$ for $10 \mathrm{~min}$ at $10{ }^{\circ} \mathrm{C}$ (Microfuge R, Beckmann). Three hundred microliters of supernatant was transferred into a HPLC crimp vial, mixed with $300 \mu \mathrm{l} \mathrm{H}_{2} \mathrm{O}$ and either directly measured or stored at $3{ }^{\circ} \mathrm{C}$ for up to 6 days. Due to varying dilutions used, the LOQs for this method were calculated to be DON: $251 \mu \mathrm{g} / \mathrm{kg}$, ZEN: $40.9 \mu \mathrm{g} / \mathrm{kg}$; $\alpha$-ZEL is $42.0 \mu \mathrm{g} / \mathrm{kg}$. Additionally, the LOD for DON is $76.1 \mu \mathrm{g} / \mathrm{kg}$, for ZEN is $12.4 \mu \mathrm{g} / \mathrm{kg}$ and for $\alpha$-ZEL is $12.8 \mu \mathrm{g} / \mathrm{kg}$.

\section{Recovery}

Spiking experiments at a level of $2 \mathrm{mg} / \mathrm{kg}$ DON and $200 \mu \mathrm{g} / \mathrm{kg}$ ZEN were performed to determine the recovery within larval and residue samples. Recovery rates found in the larval samples were determined as follows: DON $92 \pm 6 \%$ and ZEN $92 \pm 4 \%$. Additionally, recovery rates of $98 \pm 6 \%$ for DON and $94 \pm 4 \%$ for ZEN were found in the residue samples.

\section{HPLC-MS/MS instrumentation and parameters}

Analyses of wheat, larvae and residue samples was performed on an Agilent 1290 series HPLC system (Waldbronn, Germany) coupled to a Q-Trap 6500+ system (AB Sciex, Foster City, CA, USA) equipped with an IonDrive ${ }^{\mathrm{TM}}$ Turbo $V$ electrospray ionisation (ESI) source. Analytes were separated on a polar guard-coated C18 column, $100 \times 2.1 \mathrm{~mm}, 5 \mu \mathrm{m}$, (Protecol, SGE). Eluent A consisted of $\mathrm{H}_{2} \mathrm{O}, 0.1 \%$ FA and $300 \mathrm{mg} / 1 \mathrm{NH}_{4} \mathrm{COOH}$, eluent $\mathrm{B}$ was composed of methanol, $0.1 \% \mathrm{FA}$ and $300 \mathrm{mg} / 1 \mathrm{NH}_{4} \mathrm{COOH}$. After an initial period of $0.8 \mathrm{~min}$ at $15 \% \mathrm{~B}$, the proportion of B was linearly increased to $60 \%$ at $4.0 \mathrm{~min}, 65 \%$ at $6.0 \mathrm{~min}, 80 \%$ at $8.5 \mathrm{~min}$. At $11.0 \mathrm{~min}$, the proportion of $\mathrm{B}$ reached $95 \%$ which was held until $12.0 \mathrm{~min}$. At $12.5 \mathrm{~min}$, the proportion of B was lowered to $15 \%$. At a total time of $15.0 \mathrm{~min}$, the method ended. The flow rate was set to $600 \mu \mathrm{l} / \mathrm{min}$, the column temperature was $35^{\circ} \mathrm{C}$, and the injection volume was $4 \mu \mathrm{l}$. Mass spectrometric detection was performed in positive and negative ESI mode, and selected reaction monitoring was applied as scan type. For most substances, either reference standards were available (ZEN, $\alpha$-ZEL, $\beta$-ZEL, ZAN, $\beta$-ZAL, DON) or matrix samples known to contain the respective analytes ZEN14Sulf, ZEN-14-O-glucoside, ZEN-16- $O$-glucoside and $\alpha$-ZELSulf were analysed for verification of the MS parameters. Additionally, selected reaction monitoring transitions were incorporated for the analysis of hydrolysed zearalenone, decarboxylated hydrolysed zearalenone as well as ZEN- and ZEL-glucuronides based on literature data. The ESI-MS/MS parameters used are shown in Table 2.

\section{Data analyses}

Wheat, larvae and residue samples were analysed in duplicates. Analyst Software version 1.6.3 and Multiquant version 3.0.2 (Sciex, Foster City, CA, USA) were used for analyses and quantification of the data obtained. Normalisation of the data was performed for the amount of mycotoxins found in the feed/residue and weight gain of the larvae in relation to the protein content of the feed. Data for larval weight gain was tested for significance with a one-way ANOVA test followed up by a Tukey-Kramer post hoc analysis and was performed by using Excel. The calculation of the total recovery of ZEN is based on measured contents, the total amount of residue (containing faeces and not consumed feed) collected and final weight of the larvae. Recovery rates were calculated for the amount of ZEN present in the feed in relation to the amount of ZEN, $\alpha$ - and $\beta$-ZEL present in the residue (see Table 3 for detailed short-term exposure data and Table 4 for long-term exposure data).

\section{Results}

\section{Larval weight gain and survival}

In order to obtain a first impression whether the presence of ZEN has a negative effect on the health status of the insects, the weight gain and survival rates for the different feeding groups have been recorded. For all treatment groups, no significantly altered mortality rates could be observed. Neither in the treatment nor in the control groups dead insects were found.

However, the average weight increase of the larvae did differ between diets provided. Additionally, after correction for the protein content of the diets administered, larvae fed with diet $\mathrm{N} 1$ and $\mathrm{N} 2$ gained significantly more weight than larvae fed with the other diets after 8 weeks of exposure $(p<0.05)$. The 8 -week exposure of initially 6 -week old larvae led to a difference in weight gain of not more than $12 \%$ compared to the control for all spiked and artificially contaminated feed groups. For the larvae fed with naturally contaminated flour, the mean weight gain was significantly $(p<0.05)$ increased with an increase in weight of $37 \%$ for $\mathrm{N} 1$ and $62 \%$ for N2 compared to the control after 8 weeks of exposure. Figure 2a summarises the absolute differences in weight gain for all feeding groups. In order to take into account the different protein amounts in the diets as an important factor for larval growth and also for weight gain in Fig. 2b, the relative increase in weight is corrected for the higher amount of 
Table 2 Overview of selected reaction monitoring parameters

\begin{tabular}{|c|c|c|c|c|c|}
\hline Analyte & {$[\mathrm{M}-\mathrm{H}]^{-}(\mathrm{m} / \mathrm{z})$} & $\mathrm{DP}[\mathrm{V}]$ & $\begin{array}{l}\text { Product ions Q/q } \\
(\mathrm{m} / \mathrm{z})\end{array}$ & $\mathrm{CE}[\mathrm{eV}]$ & Reference(s) \\
\hline Zearalenone (ZEN) & 317.1 & -110 & $175.0 / 131.1$ & $-34 /-42$ & \\
\hline ZEN-14-O-glucuronide & 493.0 & -100 & $131.0 / 175.0$ & $-68 /-42$ & Warth et al. (2012) \\
\hline ZEN-14-sulphate (ZEN14Sulf) & 397.1 & -115 & $317.0 / 131.0$ & $-34 /-58$ & Binder et al. (2017) \\
\hline ZEN-14-O-glucoside & 479.1 & -125 & $317.1 / 175.0$ & $-22 /-54$ & Binder et al. (2017) \\
\hline ZEN-16-O-glucoside & 479.2 & -140 & $149.0 / 160.8$ & $-54 /-54$ & Binder et al. (2017) \\
\hline Hydrolysed ZEN & 335.0 & -30 & $149.0 / 161.0$ & $-30 /-30$ & Vekiru et al. (2016) \\
\hline Decarboxylated hydrolysed ZEN & 291.1 & -30 & $149.0 / 161.0$ & $-30 /-30$ & Hahn et al. (2015) \\
\hline$\alpha$-zearalenol $(\alpha$-ZEL) & 319.1 & -115 & $160.0 / 174.0$ & $-44 /-50$ & \\
\hline$\alpha$-ZEL-14-O-glucuronide & 495.1 & -110 & $319.0 / 112.8$ & $-38 /-28$ & Binder et al. (2017) \\
\hline$\alpha$-ZEL-sulphate (ZELSulf) & 399.2 & -50 & $319.2 / 275.2$ & $-25 /-40$ & Brodehl et al. (2014) \\
\hline$\beta$-zearalenol ( $\beta$-ZEL) & 319.2 & -115 & $174.0 / 160.0$ & $-50 /-44$ & \\
\hline$\beta$-ZEL-14-O-glucuronide & 495.1 & -110 & $319.0 / 112.8$ & $-38 /-28$ & Binder et al. (2017) \\
\hline$\alpha-/ \beta$-zearalanol (ZAL) & 321.2 & -75 & $277.1 / 303.2$ & $-30 /-25$ & \\
\hline Zearalanone (ZAN) & 319.2 & -75 & $275.1 / 205.0$ & $-35 /-40$ & \\
\hline Deoxynivalenol (DON) & 355.1 & -70 & $265.2 / 59.2$ & $-22 /-40$ & \\
\hline
\end{tabular}

protein available in the diet (i.e. $16 \%$ for $\mathrm{N} 1$ and $25 \%$ for N2). Still, clear difference between the N1 and N2 and the other groups after normalisation for the protein content is visible.

\section{ZEN and its reductive metabolites}

ZEN and its metabolites were not present in detectable levels in the larvae after both short- and long-term exposure (Tables 3 and 4). On the other hand, detectable levels of ZEN as well as $\alpha$ - and $\beta$-ZEL were present in all residue samples except for the control samples. The detected amount of unmetabolised ZEN in the residues accounted for $15 \%$ up to $63 \%$ of the total ZEN amount that was fed to the respective insect groups. However, the reductive ZEN metabolites $\alpha$ - and $\beta$-ZEL together account for up to another $30 \%$ of the overall ZEN intake that is recovered in the residual samples. In all cases, the quotient of $\alpha$ - and $\beta$-ZEL was varying from 0.2 and 0.6 indicating an almost constant ratio of metabolites resulting from the metabolic conversion in the T. molitor model.

Based on the mass balance data of ZEN, it becomes clear that spiked samples S1 and S2 show a higher recovery rate than artificially and naturally contaminated samples. In the 4-
Table 3 Mean, standard deviation and recovery of the amount of ZEN, $\alpha$ - and $\beta$-ZEL in $\mu \mathrm{g}$ per absolute amount of feed, larvae and residue detected after 4 weeks of exposure and $24 \mathrm{~h}$ of fasting. The toxin amount in feed was calculated individually based on the measured content (Table 1) and the individually fed amount

\begin{tabular}{|c|c|c|c|c|c|c|c|c|c|c|c|}
\hline \multirow[b]{2}{*}{ Diet code } & \multicolumn{3}{|c|}{ Feed ( $\mu$ g per amount feed) } & \multicolumn{3}{|c|}{ Worm } & \multicolumn{3}{|c|}{ Residue ( $\mu$ g per amount residue) } & \multirow[b]{2}{*}{$\begin{array}{l}\text { Recovery } \\
(\%) \text { ZEN }\end{array}$} & \multirow[b]{2}{*}{$\begin{array}{l}\text { Recovery }(\%) \\
\text { ZEN. } \alpha \text {-ZEL and } \beta \text {-ZEL }\end{array}$} \\
\hline & ZEN & $\alpha-Z E L$ & $\beta-Z E L$ & ZEN & $\alpha-Z E L$ & $\beta-Z E L$ & ZEN & $\alpha-Z E L$ & $\beta-Z E L$ & & \\
\hline
\end{tabular}

\begin{tabular}{lllllllllllll}
\hline C & $0.0 \pm 0.0$ & nd & nd & nd & nd & nd & nd & nd & nd & na & na \\
S1 & $20.0 \pm 0.9$ & nd & nd & nd & nd & nd & $7.8 \pm 0.3$ & $0.2 \pm 0.1$ & $1.0 \pm 0.2$ & 39 & 45 & \\
S2 & $76.6 \pm 2.8$ & nd & $0.1 \pm 0.1$ & nd & nd & nd & $32.7 \pm 1.3$ & $3.4 \pm 0.3$ & $6.3 \pm 0.4$ & 43 & 55 \\
A1 & $14.5 \pm 2.5$ & nd & $0.4 \pm 0.1$ & nd & nd & nd & $3.6 \pm 0.2$ & $0.5 \pm 0.1$ & $1.8 \pm 0.1$ & 25 & 41 & \\
A2 & $77.6 \pm 11.5$ & nd & $1.6 \pm 0.5$ & nd & nd & nd & $15.6 \pm 0.3$ & $3.6 \pm 0.5$ & $8.0 \pm 0.4$ & 20 & 35 & \\
N1 & $20.5 \pm 0.6$ & nd & $0.2 \pm 0.1$ & nd & nd & nd & $3.4 \pm 0.6$ & $0.7 \pm 0.2$ & $1.7 \pm 0.1$ & 17 & 28 & \\
N2 & $31.3 \pm 3.5$ & nd & $0.4 \pm 0.1$ & nd & nd & nd & $4.8 \pm 0.3$ & $1.6 \pm 0.3$ & $2.9 \pm 0.2$ & 15 & 30 & \\
\hline
\end{tabular}

$n d$ not detected, therefore either not present or not present in detectable levels (LOQs for feed were ZEN: $10.9 \mu \mathrm{g} / \mathrm{kg}$ and $\alpha$-ZEL: $11.2 \mu \mathrm{g} / \mathrm{kg}$. LOQs for worm and residue samples were ZEN: $40.9 \mu \mathrm{g} / \mathrm{kg}$ and $\alpha$-ZEL is $42.0 \mu \mathrm{g} / \mathrm{kg}$. In both cases, the LOQ of $\beta$-ZEL was comparable to $\alpha-Z E L$ and was not determined separately); $n a$ not applicable 
Table 4 Mean, standard deviation and recovery of ZEN, $\alpha$ - and $\beta$-ZEL in $\mu \mathrm{g}$ per absolute amount of feed, larvae and residue detected after 8 weeks of exposure and $24 \mathrm{~h}$ of fasting. The toxin amount in feed was calculated individually based on the measured content (Table 1) and the individually fed amount

\begin{tabular}{|c|c|c|c|c|c|c|c|c|c|c|c|}
\hline \multirow[b]{2}{*}{ Diet code } & \multicolumn{3}{|c|}{ Feed ( $\mu$ g per amount feed) } & \multicolumn{3}{|c|}{ Worm } & \multicolumn{3}{|c|}{ Residue ( $\mu$ g per amount residue) } & \multirow[b]{2}{*}{$\begin{array}{l}\text { Recovery } \\
(\%) \text { ZEN }\end{array}$} & \multirow[b]{2}{*}{$\begin{array}{l}\text { Recovery }(\%) \\
\text { ZEN. } \alpha \text {-ZEL and } \beta \text {-ZEI }\end{array}$} \\
\hline & ZEN & $\alpha-Z E L$ & $\beta-Z E L$ & ZEN & $\alpha$-ZEL & $\beta-Z E L$ & ZEN & $\alpha-Z E L$ & $\beta-Z E L$ & & \\
\hline $\mathrm{C}$ & nd & nd & nd & nd & nd & nd & nd & nd & nd & na & na \\
\hline S1 & $20.6 \pm 0.9$ & nd & nd & nd & nd & nd & $11.6 \pm 0.3$ & $0.3 \pm 0.2$ & $2.0 \pm 0.4$ & 56 & 67 \\
\hline $\mathrm{S} 2$ & $78.9 \pm 2.9$ & nd & $0.1 \pm 0.1$ & nd & nd & nd & $49.6 \pm 1.5$ & $3.8 \pm 0.3$ & $9.0 \pm 1.1$ & 63 & 79 \\
\hline A1 & $14.9 \pm 2.5$ & nd & $0.4 \pm 0.1$ & nd & nd & nd & $6.0 \pm 0.4$ & $1.2 \pm 0.1$ & $4.2 \pm 0.4$ & 40 & 77 \\
\hline A2 & $79.9 \pm 11.9$ & nd & $1.7 \pm 0.5$ & nd & nd & nd & $26.2 \pm 2.2$ & $6.8 \pm 0.7$ & $17.3 \pm 2.1$ & 33 & 63 \\
\hline N1 & $21.1 \pm 0.6$ & nd & $0.2 \pm 0.1$ & nd & nd & nd & $4.8 \pm 0.5$ & $1.8 \pm 0.4$ & $3.6 \pm 0.5$ & 23 & 49 \\
\hline $\mathrm{N} 2$ & $32.2 \pm 6.6$ & nd & $0.4 \pm 0.1$ & nd & nd & nd & $6.0 \pm 0.4$ & $3.8 \pm 0.4$ & $6.2 \pm 0.7$ & 19 & 50 \\
\hline
\end{tabular}

$n d$ not detected, therefore either not present or not present in detectable levels (LOQs for feed were ZEN: $10.9 \mu \mathrm{g} / \mathrm{kg}$ and $\alpha-\mathrm{ZEL}: 11.2 \mu \mathrm{g} / \mathrm{kg}$. LOQs for worm and residue samples were: ZEN: $40.9 \mu \mathrm{g} / \mathrm{kg}$ and $\alpha$-ZEL is $42.0 \mu \mathrm{g} / \mathrm{kg}$. In both cases, the LOQ of $\beta$-ZEL was comparable to $\alpha$-ZEL and was not determined separately); $n a$ not applicable

week feeding trial, the overall relative amount of ZEN that is recovered in the residues either as unchanged ZEN or in its reduced forms is lower than in the 8-week experiment.

Notable is the fact that $\alpha$ - and $\beta$-ZEL were detected in all residue samples, while they did not occur in all feed samples as it is shown in Fig. 3a, b exemplarily for the 8-week feeding trial using S2. The detected levels for $\alpha$ - and $\beta$-ZEL were higher in the 8-week exposed samples compared to the 4week exposed samples.

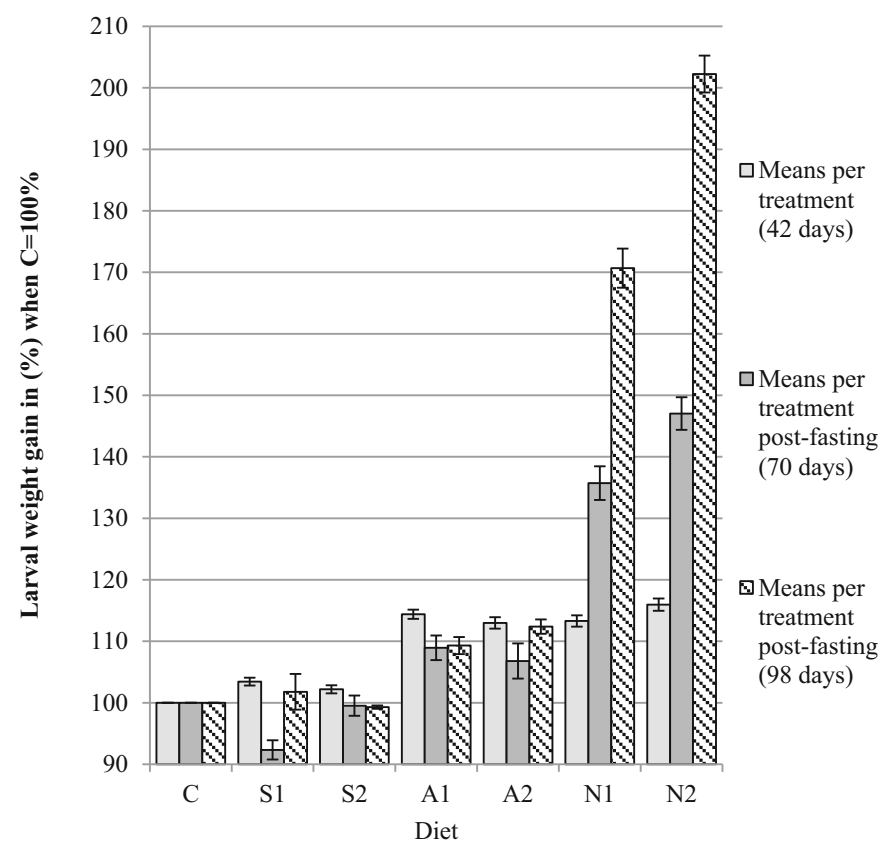

a) Larval weight gain (\%) at 70 and 98 days

\section{Phase II metabolites}

ZEN14Sulf is detectable in the naturally contaminated feed $\mathrm{N} 1$ and $\mathrm{N} 2$ as well as in the artificially contaminated feed (A1 and A2), while this compound is not detectable in the spiked or control feed (C, S1 and S2). Additionally, at least one ZELSulf signal was detectable in N1, N2 and A2 feed. No further conjugated ZEN metabolites are present in any feed. In none of the T. molitor samples, any glucuronide or sulfate

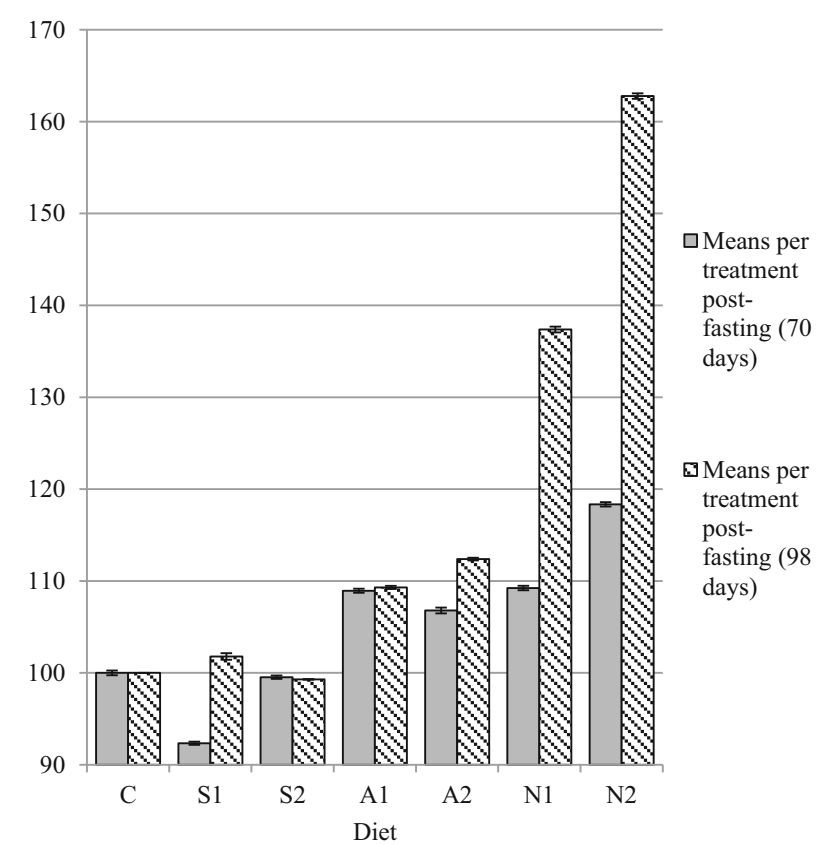

b) Larval weight gain (\%) at 70 and 98 days after normalization for diet protein content

Fig. 2 Means of larval weight gain in $\%$ of the control $(\mathrm{C}=100 \%)$ during the experimental period 


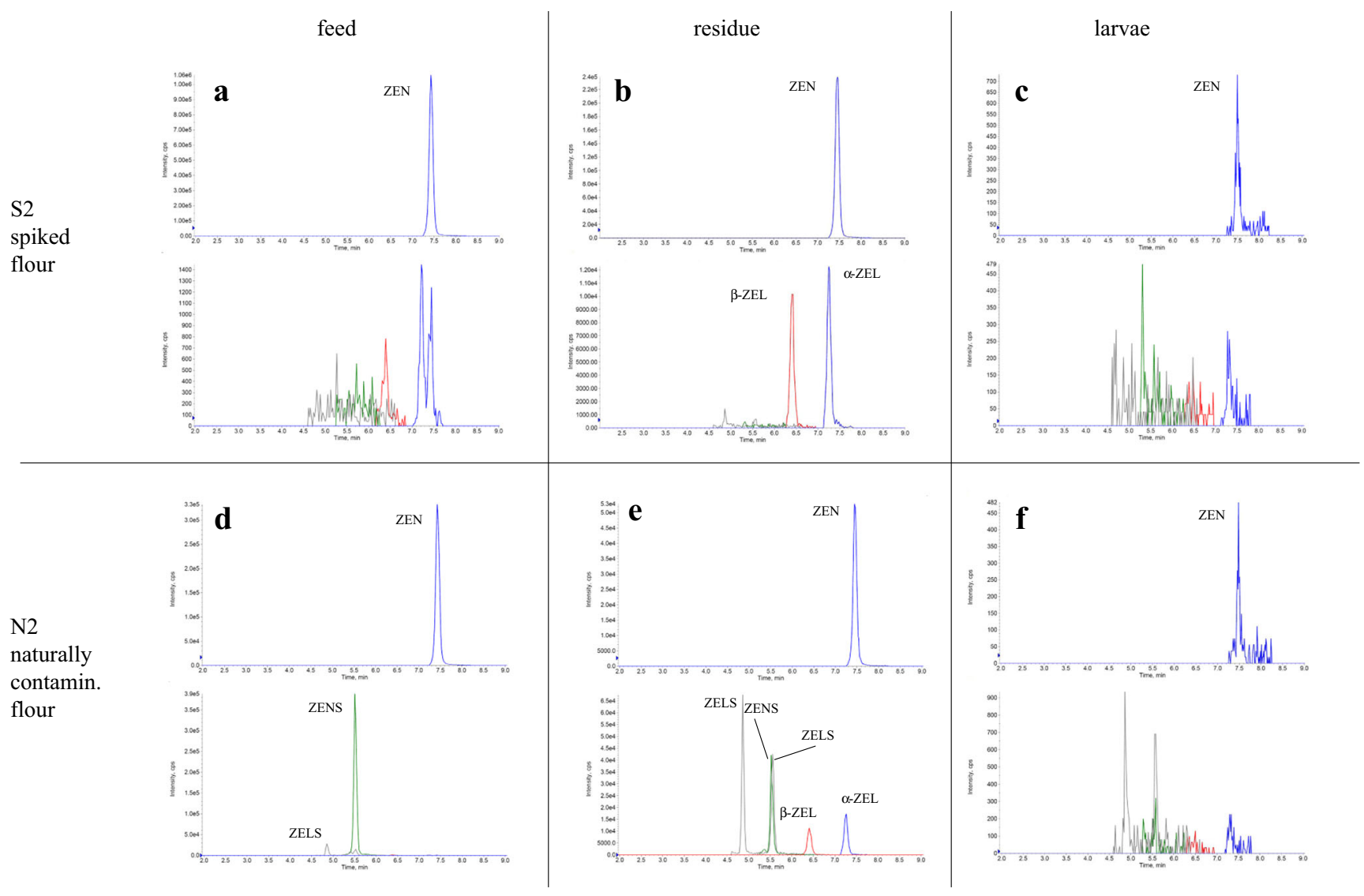

Fig. 3 Chromatograms of ZEN and ZEL presence in the feed and residue of diets S2 and N2 and the presence of ZEN14Sulf and $\alpha$ - and/or $\beta$ ZELSulf in the same samples. Chromatograms are shown for the 8 -

signals are detectable. However, regardless the exposure time of 4 or 8 weeks, in the residues of groups N1, N2 and A2 clear peaks for ZEN14Sulf as well as two different peaks for ZELSulf were detectable. By contrast, in no residue sample collected for the spiked feed groups (S1 or S2) or the control, any phase II metabolite peak of ZEN was detectable, indicating that within the T. molitor organism, no sulfation occurs (Fig. 3b). Nevertheless, the relative intensity of the ZEN14Sulf and ZELSulf signals shifted from the more intense ZEN14Sulf in feed towards the reduced metabolite ZELSulf in the residue (Fig. 3a, e). Neither for ZEN or ZEL glucosides nor the respective glucuronides, any signals could be observed in any of the HPLC-MS/MS analyses.

\section{Other mycotoxins}

As besides ZEN and ZEN14Sulf also the often co-occurring DON was present in the naturally contaminated flour and in the control flour, measurements have been carried out in all feed, T. molitor and residue samples for this toxin as well. Additionally, mass transitions specific for hydrolysed zearalenone and decarboxylated hydrolysed zearalenone as known degradation products of ZEN as well as ZAN and $\beta$ - week exposure feeding S2 and N2 exemplarily. After 4 weeks of feeding and for the diets $\mathrm{S} 1$ and $\mathrm{N} 1$ comparable but less pronounced signals could be observed

ZAL transitions were included in the HPLC-MS/MS method. For none of the aforementioned ZEN metabolites, any signals could be detected in the T. molitor samples. Also, no detectable amounts of DON were present in the larvae (Table 5). While also in the residual samples, no detectable amounts of any of the ZEN metabolites were present, DON could be detected and quantified in all residue analyses. Concerning the mass balance, the recovery of DON was around $35 \%$ after 4 weeks of exposure and $56 \%$ after 8 weeks of exposure and is found to be highest in the control and spiked samples. As DON was not within the original focus of the study, no measurements of any potential de-epoxydised or conjugate metabolites were carried out.

\section{Discussion}

The aim of the present study was to investigate the recovery of ZEN after uptake from contaminated flour by insects of the T. molitor species and to monitor its impact on the larval growth. Based on the data obtained in the present study, T. molitor larvae have a high tolerance for ZEN containing feed. This is in accordance with several other studies which 
Table 5 Mean, standard deviation and recovery of DON in $\mu \mathrm{g}$ per absolute amount of feed, larvae and residue detected after 4 weeks of exposure and $24 \mathrm{~h}$ of fasting and B) 8 weeks of exposure and $24 \mathrm{~h}$ of fasting

\begin{tabular}{|c|c|c|c|c|c|c|c|c|}
\hline \multirow[b]{2}{*}{$\begin{array}{l}\text { Diet } \\
\text { code }\end{array}$} & \multicolumn{4}{|l|}{4 weeks of exposure } & \multicolumn{4}{|l|}{8 weeks of exposure } \\
\hline & $\begin{array}{l}\text { Feed } \\
\text { ( } \mu \text { g per amount feed) }\end{array}$ & Larvae & $\begin{array}{l}\text { Residue } \\
\text { ( } \mu \mathrm{g} \text { per amount residue) }\end{array}$ & $\begin{array}{l}\text { Recovery } \\
\text { (\%) DON }\end{array}$ & $\begin{array}{l}\text { Feed } \\
\text { ( } \mu \text { g per amount feed) }\end{array}$ & Larvae & $\begin{array}{l}\text { Residue } \\
\text { ( } \mu \mathrm{g} \text { per amount residue) }\end{array}$ & $\begin{array}{l}\text { Recovery } \\
(\%) \text { DON }\end{array}$ \\
\hline $\mathrm{C}$ & $19.4 \pm 0.7$ & nd & $7.3 \pm 0.2$ & 37 & $20.0 \pm 0.7$ & nd & $14.1 \pm 0.1$ & 71 \\
\hline $\mathrm{S} 1$ & $19.3 \pm 2.4$ & nd & $7.1 \pm 1.0$ & 37 & $19.9 \pm 2.5$ & nd & $11.5 \pm 0.6$ & 58 \\
\hline $\mathrm{S} 2$ & $19.6 \pm 0.8$ & nd & $6.6 \pm 0.4$ & 34 & $20.2 \pm 0.8$ & nd & $11.7 \pm 1.3$ & 58 \\
\hline A1 & $31.9 \pm 2.2$ & nd & $10.8 \pm 1.0$ & 34 & $32.9 \pm 2.2$ & nd & $18.5 \pm 1.3$ & 56 \\
\hline $\mathrm{A} 2$ & $71.4 \pm 5.6$ & nd & $23.3 \pm 1.6$ & 33 & $73.5 \pm 5.7$ & nd & $39.3 \pm 2.3$ & 53 \\
\hline N1 & $97.0 \pm 2.9$ & nd & $27.9 \pm 2.8$ & 29 & $99.9 \pm 3.0$ & nd & $51.6 \pm 1.5$ & 52 \\
\hline N2 & $156.0 \pm 14.3$ & nd & $38.4 \pm 3.3$ & 38 & $160.6 \pm 14.7$ & nd & $73.9 \pm 10.4$ & 46 \\
\hline
\end{tabular}

$n d$ not detected, therefore either not present or not present in detectable levels (LOQs for DON $67.1 \mu \mathrm{g} / \mathrm{kg}$ in feed and $251 \mu \mathrm{g} / \mathrm{kg}$ in residue)

showed that T. molitor larvae can be grown on a mycotoxincontaining diet without increased mortality (Abado-Becognee et al. 1998; Davis and Schiefer 1982; Guo et al. 2014). The naturally contaminated diet containing up to approx. $4600 \mu \mathrm{g} / \mathrm{kg}$ DON and $900 \mu \mathrm{g} / \mathrm{kg}$ ZEN even led to an apparently higher weight gain in the larvae.

As the feed prepared from naturally contaminated grains was more protein rich compared to the other diets, larval weight gain was corrected for the elevated protein content of the feed in N1 and N2, as the availability of protein from the feed may impact on larval weight gain. Davis and Schiefer (1982) suggested the normalisation for larvae of T. molitor to take into account the protein effect on the growth when monitoring the effects of T-toxin exposure (Davis and Schiefer 1982). Protein contents of the diets C, A2, N2 were measured and protein content for the further diets prepared by using different ratios of the aforementioned feed were mathematically derived. ZEN spiking (S1 and S2) was assumed to have no impact on the protein content. After normalisation for the protein content, still a significant higher weight gain was found in larvae fed on a naturally contaminated diet for 8 weeks. Therefore, the presence of the fungus or other beneficial fungal secondary products seems to be responsible for an enhanced growth. Other studies showed no significant difference but a strong tendency for an enhanced weight gain when comparing $T$. molitor larvae grown on a naturally DON-contaminated diet versus a spiked or DONuncontaminated control diet (Van Broekhoven et al. 2017). Also, the presence of aflatoxin B1 (AFB1) in feed did not show a significant difference in weight gain of black soldier fly larvae (Hermetia illucens) and T. molitor larvae when fed on either AFB1-containing feed or AFB1-free feed (Bosch et al. 2017). Guo et al. (2014) showed that T. molitor larvae are significantly more attracted to wheat colonised with Fusarium spp. proliferatum, poae and the ZEN-producing Fusarium culmorum compared to a control. Avoidance or preference for the infested wheat was correlated with feeding behaviour and larval weight gain (Guo et al. 2014). Eventually, such feed contains micronutrients that enables for a faster growth and better feed conversion. It might be hypothesised that during evolution, some insects like T. molitor have gained the capability to sense such grains infested with fungi that provide additive nutritional value. In turn, the increased feeding preference might be due to the specific capability of Fusarium strains to actively attract T. molitor. The larvae have been shown to enhance the dissemination of $F$. proliferatum by carrying the fungus in the digestive tract or adherent to the larval body (Guo et al. 2018). Our study is also in line with van Broekhoven et al. (2017) who could show that not the spiked mycotoxin alone but only naturally contaminated grain material possesses additional attractiveness for the larvae (Van Broekhoven et al. 2017).

Like previously reported for other mycotoxins such as AFB1 and DON, also the present experiment shows that in some feeding groups, more than $50 \%$ of the presumably ingested ZEN remained undetected after analysis of the insects, the unconsumed feed as well as the larval faeces (Bosch et al. 2017; Van Broekhoven et al. 2017).

For the first time, the present study included known phase I and II metabolites of ZEN and DON in the LC-MS/MS analysis. However, due to the lack of available standards for several metabolites, only qualitative analyses could be performed. Based on experience from prior work, the sensitivity for glucuronides should not differ strongly from the parent compound (Warth et al. 2012). Additionally, sulfates should be detectable with much higher sensitivity in ESI-MS analysis (Borzekowski et al. 2018). Thus, it is expected that no large quantities of ZEN phase II metabolites should have been missed during analyses. Anyway, the absence of any detectable signals of ZEN14Sulf or ZELSulf in the feeding group S1 and S2 implies that no sulfation occurs during metabolic conversion of ZEN in T. molitor larvae. On the other hand, the shift from the dominant ZEN14Sulf signal in naturally contaminated feed towards equal signal intensities for two distinct 
reductive ZELSulf metabolites compared to ZEN14Sulf in the residue samples shows that not only free ZEN but also ZEN14Sulf is converted either in the insect or due to the influence of intestinal bacteria coming into contact with unconsumed feed after excretion with the faeces.

Additionally, a higher excretion of ZEN and DON was found in the residue of the spiked samples compared to the artificially and naturally contaminated samples. Similar results were found in the study of van Broekhoven et al. (2017), who found a higher excretion of DON in T. molitor larval faeces for the DON-spiked diet compared to the naturally contaminated diet fed to larvae (Van Broekhoven et al. 2017).

Overall, no ZEN or ZEN metabolite accumulation was detected in any of the larval groups in this study. Furthermore, after the experimental and 24-h fasting period, no ZEN-related substances could be detected in the insects. Thus, all of the monitored substances are efficiently and rapidly excreted from the organism. Also, Guo et al. (2014) and van Broekhoven et al. (2017) did not detect any DON or DON derivatives in T. molitor larvae fed with infested wheat (Guo et al. 2014; Van Broekhoven et al. 2017). However, it cannot be excluded that non-detection is due to the fact that metabolites were formed which do not fall in the scope of this study.

The present study suggests that transformation of either ZEN to ZEL or ZEN14Sulf to ZELSulf but no sulfation takes place during larval metabolism. This is in accordance with a study of Camenzuli et al. (2018) who showed that $\alpha$ - and $\beta$ ZEL were detected in the residue of black soldier fly larvae (H. illucens), while only ZEN was present in the initial feed (Camenzuli et al. 2018). Similar results were also found by Keller et al. (2018) who observed that the nematode C. elegans metabolised ZEN into $\alpha$ - and/or $\beta$-ZEL, while ZEN14Sulf was metabolised in $\alpha$ - and/or $\beta$-ZELSulf (Keller et al. 2018). The research performed by Kostaropoulos et al. (1996) shows that detoxification enzymes are present in T. molitor, which makes ZEN metabolism in larvae possible (Kostaropoulos et al. 1996). However, also other biotransformation reactions catalysed by the larvae themselves or by bacteria colonising, the larval digestion tract could be considered. Within the present study, the amount of $\alpha$ - and $\beta$-ZEL found in the residue is in all cases double as much for $\beta$-ZEL, compared to $\alpha$-ZEL. The aforementioned is in accordance with data found in previous performed research, where it was shown that metabolism of ZEN into $\alpha$ - and/or $\beta$-ZEL occurs in different ratios depending on the animal species (Yang et al. 2017). It is known that $\alpha$-derivatives are more abundant in dogs, pigs and turkey, while the $\beta$-derivatives are more prevailing in goats, horses, cattle and laying hens (EFSA 2017). Mammal species including humans predominantly form the conjugated ZEN or ZEL sulfates and glucuronides that appear to be absent in insects or nematodes despite the fact that, e.g. insects possess enzymes of the sulfotransferase class which would in principle enable them to for e.g. ZEN14Sulf formation (Pfeiffer et al. 2010, 2011; Zöllner et al. 2002). Further studies on the metabolism of ZEN showed that Fusarium graminearum, Aspergillus niger and Rhizopus arrhizus can transform ZEN into ZEN14Sulf and presented the formation of glucosides and sulfates by several Aspergillus oryzae strains and Rhizopus species (Brodehl et al. 2014; el-Sharkawy et al. 1991). For ZEN, at least it becomes obvious that the phase I metabolism shows clear similarity to other species investigated earlier while none of those animal or microorganism models had a similar outcome for the phase II metabolism shown in our feeding trial with T. molitor.

From the food and feed safety perspective, our data enforces the findings published for the fate of ZEN in other insect species such as larvae of black soldier fly (H. illucens) and lesser mealworm (A. diaperinus). The vast majority of ingested toxin is rapidly excreted and having in mind the common application of an at least 24-h fasting period before harvesting the larvae, the remaining ZEN as well as its metabolites should be negligible in the insects.

Although neither ZEN nor its reductive metabolites are detectable in the T. molitor, the intense formation of the more potent oestrogen $\alpha$-ZEL might impact on the organism. It should be investigated in how far oestrogenic substances could impair the pupation of the larvae and thus negatively influence the reproduction process of T. molitor to avoid negative effects on the stable reproduction capability when the insect is used for feed production (McCallum et al. 2013; Roy et al. 2007).

Acknowledgments This project is supported via AIF (27 LN/1) within the programme of promoting the Industrial Collective Research (IGF) of the German Ministry of Economics and Energy (BMWi), based on a resolution of the German Parliament. Furthermore, the authors acknowledge Sebastian Demtröder for his assistance in the T. molitor handling.

\section{Compliance with ethical standards}

\section{Conflicts of interest None.}

Open Access This article is distributed under the terms of the Creative Commons Attribution 4.0 International License (http:// creativecommons.org/licenses/by/4.0/), which permits unrestricted use, distribution, and reproduction in any medium, provided you give appropriate credit to the original author(s) and the source, provide a link to the Creative Commons license, and indicate if changes were made.

Publisher's note Springer Nature remains neutral with regard to jurisdictional claims in published maps and institutional affiliations.

\section{References}

Abado-Becognee K, Fleurat-Lessard F, Creppy EE, Melcion D (1998) Effects of fumonisin B1 on growth and metabolism of larvae of the yellow mealworm, Tenebrio molitor. Entomol Exp Appl 86:135143. https://doi.org/10.1046/j.1570-7458.1998.00274.x 
Ahn S, Vogel H, Heckel DG (2012) Comparative analysis of the UDPglycosyltransferase multigene family in insects. Insect Biochem Mol Biol 42:133-147. https://doi.org/10.1016/j.ibmb.2011.11.006

Berthiller F, Schuhmacher R, Adam G, Krska R (2009) Formation, determination and significance of masked and other conjugated mycotoxins. Anal Bioanal Chem 395:1243-1252. https://doi.org/10. 1007/s00216-009-2874-x

Berthiller F, Crews C, Dall'Asta C, Saeger SD, Haesaert G, Karlovsky P, Oswald IP, Seefelder W, Speijers G, Stroka J (2013) Masked mycotoxins: a review. Mol Nutr Food Res 57:165-186. https://doi.org/10. 1002/mnfr.201100764

Bhatnagar D, Lillehoj E, Arora D (1991) Handbook of applied mycology: volume 5: mycotoxins in ecological systems, vol 5. CRC Press/ Taylor \& Francis Group

Binder SB, Schwartz-Zimmermann HE, Varga E, Bichl G, Michlmayr H, Adam G, Berthiller F (2017) Metabolism of zearalenone and its major modified forms in pigs. Toxins 9:56. https://doi.org/10. 3390/toxins 9020056

Borzekowski A, Drewitz T, Keller J, Pfeifer D, Kunte HJ, Koch M, Rohn S, Maul R (2018) Biosynthesis and characterization of zearalenone14-sulfate, zearalenone-14-glucoside and zearalenone-16-glucoside using common fungal strains. Toxins (Basel) 10:104. https://doi.org/ 10.3390/toxins 10030104

Bosch G, van der Fels-Klerx HJ, de Rijk TC, Oonincx DGAB (2017) Aflatoxin B1 tolerance and accumulation in black soldier fly larvae (Hermetia illucens) and yellow mealworms (Tenebrio molitor). Toxins 9:185. https://doi.org/10.3390/toxins9060185

Bovera F, Piccolo G, Gasco L, Marono S, Loponte R, Vassalotti G, Mastellone V, Lombardi P, Attia YA, Nizza A (2015) Yellow mealworm larvae (Tenebrio molitor, L.) as a possible alternative to soybean meal in broiler diets. Br Poult Sci 56:569-575. https://doi.org/ 10.1080/00071668.2015.1080815

Brodehl A, Moller A, Kunte HJ, Koch M, Maul R (2014) Biotransformation of the mycotoxin zearalenone by fungi of the genera Rhizopus and Aspergillus. FEMS Microbiol Lett 359:124 130. https://doi.org/10.1111/1574-6968.12586

Camenzuli L, Van Dam R, de Rijk T, Andriessen R, Van Schelt J, Van der Fels-Klerx HJ (2018) Tolerance and excretion of the mycotoxins aflatoxin $\mathrm{B}(1)$, zearalenone, deoxynivalenol, and ochratoxin a by Alphitobius diaperinus and Hermetia illucens from contaminated substrates. Toxins 10:91. https://doi.org/10.3390/toxins10020091

Davis GRF, Schiefer HB (1982) Effects of dietary T-2 toxin concentrations fed to larvae of the yellow mealworm at three dietary protein levels. Comp Biochem Physiol Biochem Mol Biol Part C Comp Pharmacol 73:13-16. https://doi.org/10.1016/0306-4492(82) 90159-9

Dinan L, Bourne P, Whiting P, Dhadialla TS, Hutchinson TH (2001) Screening of environmental contaminants for ecdysteroid agonist and antagonist activity using the Drosophila melanogaster B(II) cell in vitro assay. Environ Toxicol Chem 20:2038-2046

Dubos T, Pasquali M, Pogoda F, Hoffmann L, Beyer M (2011) Evidence for natural resistance towards trifloxystrobin in Fusarium graminearum. Eur J Plant Pathol 130:239-248. https://doi.org/10. 1007/s10658-011-9749-7

EFSA (2011) Scientific opinion on the risks for public health related to the presence of zearalenone in food. EFSA J 9:1-124. https://doi. org/10.2903/j.efsa.2011.2197

EFSA (2016) Appropriateness to set a group health-based guidance value for zearalenone and its modified forms. EFSA J 14:1-46. https://doi. org/10.2903/j.efsa.2016.4425

EFSA (2017) Risks for animal health related to the presence of zearalenone and its modified forms in feed. EFSA J 15:1-123. https://doi.org/10.2903/j.efsa.2017.4851

el-Sharkawy SH, Selim MI, Afifi MS, Halaweish FT (1991) Microbial transformation of zearalenone to a zearalenone sulfate. J Appl Environ Microbiol 57:549-552
European Commission (2017) Commission regulation (EU) 2017/893. OJ 138:92-116

European Parliament and the Council of the European Union (2009a) Regulation (EC) 767/2009. OJ 229:1-28

European Parliament and the Council of the European Union (2009b) Regulation (EC) 1069/2009. OJ 300:1-33

European Parliament and the Council of the European Union (2015) Regulation (EU) 2015/2283. OJ 327:1-22

Foley JA, Ramankutty N, Brauman KA, Cassidy ES, Gerber JS, Johnston M, Mueller ND, O'Connell C, Ray DK, West PC, Balzer C, Bennett EM, Carpenter SR, Hill J, Monfreda C, Polasky S, Rockström J, Sheehan J, Siebert S, Tilman D, Zaks DPM (2011) Solutions for a cultivated planet. Nature 478:337-342. https://doi.org/10.1038/ nature 10452

Godfray HC et al (2010) Food security: the challenge of feeding 9 billion people. Science (New York, NY) 327:812-818. https://doi.org/10. 1126/science. 1185383

Guerre P (2015) Fusariotoxins in avian species: toxicokinetics, metabolism and persistence in tissues. Toxins 7:2289-2305. https://doi.org/ $10.3390 /$ toxins 7062289

Guo Z, Döll K, Dastjerdi R, Karlovsky P, Dehne HW, Altincicek B (2014) Effect of fungal colonization of wheat grains with Fusarium spp. on food choice, weight gain and mortality of meal beetle larvae (Tenebrio molitor). PLoS One 9:1-9. https://doi.org/ 10.1371/journal.pone.0100112

Guo Z, Pfohl K, Karlovsky P, Dehne H-W, Altincicek B (2018) Dissemination of Fusarium proliferatum by mealworm beetle Tenebrio molitor. PLoS One 13:e0204602. https://doi.org/10.1371/ journal.pone. 0204602

Hagler WM, Mirocha CJ, Pathre SV, Behrens JC (1979) Identification of the naturally occurring isomer of zearalenol produced by Fusarium roseum 'Gibbosum' in rice culture. J Appl Environ Microbiol 37: 849-853

Hahn I, Kunz-Vekiru E, Twarużek M, Grajewski J, Krska R, Berthiller F (2015) Aerobic and anaerobic testing of feed additives claiming to detoxify deoxynivalenol and zearalenone. Food Additives \& Contaminants: Part A 32(6):922-933

Hoogenboom LA et al (2008) Contaminants and microorganisms in Dutch organic food products: a comparison with conventional products. Food Addit Contam Part A Chem Anal Control Expo Risk Assess 25:1195-1207. https://doi.org/10.1080/ 02652030802014930

Hueza IM, Raspantini PCF, Raspantini LER, Latorre AO, Górniak SL (2014) Zearalenone, an estrogenic mycotoxin, is an immunotoxic compound. Toxins 6:1080-1095. https://doi.org/10.3390/ toxins 6031080

Hussein H, Brasel J (2001) Toxicity, metabolism, and impact of mycotoxins on humans and animals. Toxicology 167:101-134. https:// doi.org/10.1016/S0300-483X(01)00471-1

Ji C, Fan Y, Zhao L (2016) Review on biological degradation of mycotoxins. Anim Nutr 2:127-133. https://doi.org/10.1016/j.aninu.2016. 07.003

Keller J, Borzekowski A, Haase H, Menzel R, Rueß L, Koch M (2018) Toxicity assay for citrinin, zearalenone and zearalenone-14-sulfate using the nematode Caenorhabditis elegans as model organism. Toxins 10:284. https://doi.org/10.3390/toxins 10070284

Kinani S, Bouchonnet S, Bourcier S, Porcher JM, Ait-Aissa S (2008) Study of the chemical derivatization of zearalenone and its metabolites for gas chromatography-mass spectrometry analysis of environmental samples. J Chromatogr A 1190:307-315. https://doi.org/10. 1016/j.chroma.2008.02.115

Kostaropoulos I, Mantzari AE, Papadopoulos AI (1996) Alterations of some glutathione S-transferase characteristics during the development of Tenebrio molitor (Insecta: Coleoptera). Insect Biochem Mol Biol 26:963-969. https://doi.org/10.1016/S0965-1748(96) 00063-X 
Makkar HPS, Tran G, Heuzé V, Ankers P (2014) State-of-the-art on use of insects as animal feed. Anim Feed Sci Technol 197:1-33. https:// doi.org/10.1016/j.anifeedsci.2014.07.008

Malekinejad H, Maas-Bakker R, Fink-Gremmels J (2006) Species differences in the hepatic biotransformation of zearalenone. Vet J 172:96102. https://doi.org/10.1016/j.tvj1.2005.03.004

Maul R, Warth B, Kant JS, Schebb NH, Krska R, Koch M, Sulyok M (2012) Investigation of the hepatic glucuronidation pattern of the Fusarium mycotoxin deoxynivalenol in various species. Chem Res Toxicol 25:2715-2717. https://doi.org/10.1021/tx300348x

McCallum ML, Matlock M, Treas J, Safi B, Sanson W, McCallum JL (2013) Endocrine disruption of sexual selection by an estrogenic herbicide in the mealworm beetle (Tenebrio molitor). Ecotoxicology 22:1461-1466. https://doi.org/10.1007/s10646-013$1132-3$

Metzler M, Pfeiffer E, Hildebrand A (2010) Zearalenone and its metabolites as endocrine disrupting chemicals. World Mycotoxin J 3:385401. https://doi.org/10.3920/wmj2010.1244

Pfeiffer E, Schebb NH, Podlech J, Metzler M (2007) Novel oxidative in vitro metabolites of the mycotoxins alternariol and alternariol methyl ether. Mol Nutr Food Res 51:307-316. https://doi.org/10. $1002 / \mathrm{mnfr} .200600237$

Pfeiffer E, Hildebrand A, Mikula H, Metzler M (2010) Glucuronidation of zearalenone, zeranol and four metabolites in vitro: formation of glucuronides by various microsomes and human UDPglucuronosyltransferase isoforms. Mol Nutr Food Res 54:14681476. https://doi.org/10.1002/mnfr.200900524

Pfeiffer E, Kommer A, Dempe JS, Hildebrand AA, Metzler M (2011) Absorption and metabolism of the mycotoxin zearalenone and the growth promotor zeranol in Caco-2 cells in vitro. Mol Nutr Food Res 55:560-567. https://doi.org/10.1002/mnfr.201000381

Prelusky DB, Veira DM, Trenholm HL, Hartin KE (1986) Excretion profiles of the mycotoxin deoxynivalenol, following oral and intravenous administration to sheep. Fundam Appl Toxicol 6:356-363

Roy S, De J, Kundu S, Biswas A, Pramanik M, Ray AK (2007) Estradiol$17 \beta$ : tracing its metabolic significance in female fatbody of fifth instar larvae of silkworm, Bombyx mori L (race: Nistari). Life Sci 80:446-453. https://doi.org/10.1016/j.1fs.2006.09.032

Rumpold BA, Schluter OK (2013) Nutritional composition and safety aspects of edible insects. Mol Nutr Food Res 57:802-823. https:// doi.org/10.1002/mnfr.201200735

Rychlik M, Humpf HU, Marko D, Dänicke S, Mally A, Berthiller F, Klaffke H, Lorenz N (2014) Proposal of a comprehensive definition of modified and other forms of mycotoxins including "masked" mycotoxins. Mycotoxin Res 30:197-205. https://doi.org/10.1007/ s12550-014-0203-5

Schollenberger M, Müller H-M, Rüfle M, Suchy S, Plank S, Drochner W (2006) Natural occurrence of 16 Fusarium toxins in grains and feedstuffs of plant origin from Germany. Mycopathologia 161:43-52. https://doi.org/10.1007/s11046-005-0199-7

Scudamore KA, Patel S (2000) Survey for aflatoxins, ochratoxin a, zearalenone and fumonisins in maize imported into the United Kingdom. Food Addit Contam 17:407-416. https://doi.org/10. 1080/026520300404824

Shier WT, Shier AC, Xie W, Mirocha CJ (2001) Structure-activity relationships for human estrogenic activity in zearalenone mycotoxins. Toxicon 39:1435-1438
Swevers L, Lambert JGD, De Loof A (1990) Hydroxysteroid dehydrogenase activity in tissues of two insect species. Comp Biochem Physiol B Biochem Mol Biol 97:735-739. https://doi.org/10.1016/ 0305-0491(90)90115-A

Vakiani E, Luz JG, Buck J (1998) Substrate specificity and kinetic mechanism of the insect sulfotransferase, retinol dehydratase. J Biol Chem 273:35381-35387. https://doi.org/10.1074/jbc.273.52.35381

Van Broekhoven S, Mota Gutierrez J, De Rijk T, De Nijs W, Van Loon J (2017) Degradation and excretion of the Fusarium toxin deoxynivalenol by an edible insect, the yellow mealworm (Tenebrio molitor L.). World Mycotoxin J 10:163-169. https://doi. org/10.3920/wmj2016.2102

Van der Fels-Klerx HJ, Camenzuli L, Lee M, Oonincx D (2016) Uptake of cadmium, lead and arsenic by Tenebrio molitor and Hermetia illucens from contaminated substrates. PLoS One 11:1-13. https:// doi.org/10.1371/journal.pone.0166186

van Huis A (2013) Potential of insects as food and feed in assuring food security. Annu Rev Entomol 58:563-583. https://doi.org/10.1146/ annurev-ento-120811-153704

van Huis A, Van Itterbeeck J, Klunder H, Mertens E, Halloran A, Muir G, Vantomme P (2013) Edible insects: future prospects for food and feed security. Food and agriculture Organization of the United Nations (FAO), Rome, Italy. FAO forestry paper 171:1-201

van Raamsdonk LWD, van der Fels-Klerx HJ, de Jong J (2017) New feed ingredients: the insect opportunity. Food Addit Contam Part A Chem Anal Control Expo Risk Assess 34:1384-1397. https://doi. org/10.1080/19440049.2017.1306883

Vekiru E, Fruhauf S, Hametner C, Schatzmayr G, Krska R, Moll WD, Schuhmacher R (2016) Isolation and characterisation of enzymatic zearalenone hydrolysis reaction products. World Mycotoxin J 9(3): 353-363

Warth B, Sulyok M, Fruhmann P, Mikula H, Berthiller F, Schuhmacher R, Hametner C, Abia WA, Adam G, Fröhlich J, Krska R (2012) Development and validation of a rapid multi-biomarker liquid chromatography/tandem mass spectrometry method to assess human exposure to mycotoxins. Rapid Commun Mass Spectrom 26: 1533-1540. https://doi.org/10.1002/rcm.6255

Warth B, Fruhmann P, Wiesenberger G, Kluger B, Sarkanj B, Lemmens M, Hametner C, Fröhlich J, Adam G, Krska R, Schuhmacher R (2015) Deoxynivalenol-sulfates: identification and quantification of novel conjugated (masked) mycotoxins in wheat. Anal Bioanal Chem 407:1033-1039. https://doi.org/10.1007/s00216-014-8340-4

Yang S, Zhang H, Sun F, de Ruyck K, Zhang J, Jin Y, Li Y, Wang Z, Zhang S, de Saeger S, Zhou J, Li Y, de Boevre M (2017) Metabolic profile of zearalenone in liver microsomes from different species and its in vivo metabolism in rats and chickens using ultra highpressure liquid chromatography-quadrupole/time-of-flight mass spectrometry. J Agric Food Chem 65:11292-11303. https://doi. org/10.1021/acs.jafc.7b04663

Zöllner P, Jodlbauer J, Kleinova M, Kahlbacher H, Kuhn T, Hochsteiner W, Lindner W (2002) Concentration levels of zearalenone and its metabolites in urine, muscle tissue, and liver samples of pigs fed with mycotoxin-contaminated oats. J Agric Food Chem 50:2494-2501 